\title{
A perinatal mortality survey in south-east London, 1970-73: the pathological findings in 726 necropsies
}

\author{
G. A. MACHIN
}

From the Paediatric Research Unit, Guy's Hospital Medical School, London SEI ${ }^{1}$

SYNOPSIS The primary necropsy findings are presented for 726 perinatal deaths; the classification of the 1958 British Perinatal Mortality Survey is used, and the results of the two surveys are compared. Lethal malformation has replaced intrapartum hypoxia as the most common cause of: perinatal death. There has been a substantial reduction in intracranial trauma but an increase inస్ intraventricular haemorrhage and, possibly, extrapulmonary infection.

Chromosome abnormalities occurred in 28 of 500 karyotyped infants $(5.6 \%)$. Indications for $\stackrel{\circ}{\lrcorner}$ genetic counselling, and antenatal diagnosis in any subsequent pregnancy, were apparent in $10 \%$ of $ᄃ$ cases.

The British Perinatal Mortality Survey collected clinical and pathological data on over 7000 infants who died in the perinatal period during March, April, and May 1958. The data were presented in two reports (Butler and Bonham, 1963; Butler and Alberman, 1969). More recent publications have considered epidemiological and aetiological factors in certain of the neonatal deaths in 1958 (Fedrick and Butler, 1970a, b; 1971a, b, c). Apart from some data on perinatal mortality in the Newcastle City maternity survey (Fairweather et al, 1966), and from the British Births Survey, 1970 (Claireaux, 1973), surprisingly little has been published on the pathology of perinatal mortality in the United Kingdom since 1958.

At present it seems that three factors may cause a significant reduction in perinatal mortality over the next few years: first, reliable methods of preventing or reversing the spontaneous premature onset of labour would reduce the number of deaths from the pulmonary complications of prematurity; secondly, it is now possible to assess the maturity of foetal lungs in utero, measuring the lecithin/sphingomyelin ratio (Gluck et $a l, 1971$ ), and to promote pulmonary maturation (Liggins and Howie, 1972) where early induction of labour is indicated; thirdly, the antenatal diagnosis of certain genetically determined diseases will become common, with a consequent reduction in their contribution to perinatal death.

It is therefore opportune to present the pathologi-

${ }^{1}$ Present address: Department of Pathology, Royal Hospital for Sick Children, Sciennes Road, Edinburgh EH9 1LF

Received for publication 7 January 1975. cal findings of a survey of 726 necropsied perinatal deaths during the period 1970-73. One of the objectives of this survey was to determine the incidence of major chromosome abnormalities in infants dying in the perinatal period, and to relate these to the clinical features and pathological findings (Machin, $\varrho$ 1974).

\section{Materials and Methods}

The 726 infants were born in nine hospital groups in a continuous geographical area of south and south-? east London, including inner and outer boroughs of 3 . Greater London, between September 1970 and June 8 1973. The area served by the survey was increased in $\frac{3}{3}$ two stages until it covered the boroughs of Bromley, o Greenwich, Lambeth, Lewisham, Southwark, and Tower Hamlets. One-fifth of all births in Greater $\frac{7}{0}$ London take place in these boroughs (Registrar General's Statistical Report for England and Wales, $\sigma$ 1971); and 90\% of births in England in 1972 took N place in National Health Service hospitals (Depart- N ment of Health and Social Security, 1973), including the great majority ascertained as being at risk for perinatal death. The area included specialist centres for Rhesus disease, neonatal surgery, and the manage- $\cong$ ment of diabetic pregnancies. Only cases referred to these units from other hospitals within the survey area have been included in the analysis. A few sick neonates were referred to specialist units outside the area, but it was only rarely possible to trace necropsied cases for inclusion in the survey.

The author carried out necropsies on the majority 
of these infants and obtained pathological and clinical data on the remainder. The primary necropsy categories used were those of the 1958 British Perinatal Mortality Survey, and direct comparisons could thus be made. These categories are as follows:

\section{1 lethal malformation}

2 iso-immunization. These were cases where there was maternofoetal blood group incompatibility, with appropriate necropsy findings, namely, jaundice and/or hydrops foetalis.

3 antepartum death without a major lesion. These infants were macerated and showed no recognizable evidence of malformation or of other disease.

4 antepartum hypoxia. These were macerated stillborn infants in whom evidence of hypoxia could nevertheless be seen, namely, petechial haemorrhages on the surfaces of the thoracic viscera, and histological evidence of inhalation of squames and/or meconium.

5 intrapartum hypoxia. These infants were stillborn in fresh condition or died early in the neonatal period with evidence of hypoxia, as in category 3 . Infants were assigned to this category even if there was no evident clinical cause for the hypoxia.

6 intrapartum hypoxia with cerebral birth trauma. These infants were stillborn or died in the early neonatal period with subdural haemorrhage resulting from torn tentorium and/or falx. They also had evidence of hypoxia, as in category 5 .

7 cerebral birth trauma alone

8 pulmonary infection. These were infants whose lungs contained exudates of polymorphonuclear leucocytes, sometimes with bronchopneumonia or frank abscess formation.

9 hyaline membrane disease. The lungs of these infants showed widespread alveolar collapse while the few expanded air spaces were lined by eosinophilic hyaline membrane material. Many such infants actually died of intraventricular haemorrhage (IVH), and hyaline membrane disease was considered the primary necropsy finding only in the absence of IVH.

10 massive pulmonary haemorrhage. This lesion was found in neonates whose lungs were very heavy and had the colour and consistency of blood clots. There was often blood in the trachea and bronchi. Microscopically there was widespread severe intraalveolar and interstitial haemorrhage.

11 intraventricular haemorrhage. These infants had haemorrhage arising from subependymal haematomata and occupying the ventricular system and cisterna magna.

12 neonatal death without a major lesion. These neonates were of short gestation and lacked any apparent macroscopic or microscopic lesion.
13 extrapulmonary infection, including meningitis and septicaemia

14 intrapartum death without major lesion. There were no such infants in this survey.

15 miscellaneous. These infants had comparatively rare lesions that did not fit into the major categories above.

Tissue blocks were taken for histology, as recommended by Langley (1971), and particular attention was directed to pulmonary histology.

Body weights were compared with data obtained from the British Perinatal Mortality Survey, 1958 (Butler and Alberman, 1969, appendix table 4.26). Organ weights were assessed using the data of Gruenwald and Minh (1960).

Chromosome preparations were made by culturing solid organs taken at the time of necropsy. Gonad was used in the case of neonates and intrapartum deaths, and amnion from the surface of the placenta gave results from some antepartum and intrapartum deaths. Results were generally obtained after about three weeks and were reported to the clinicians. Genetic counselling, family studies, and antenatal diagnosis were offered as indicated.

\section{Results}

PRIMARY NECROPSY FINDINGS

There were 185 antepartum deaths $(25 \%), 161$ intrapartum deaths $(22 \%)$, and 380 early neonatal deaths $(53 \%)$. In 1958, the comparable figures were 28,37 , and $35 \%$ respectively. Table I analyses each primary necropsy finding by sex and stage of death.

Malformation was the largest group, followed by the antepartum and intrapartum anoxic deaths. Males predominated among hypoxic and traumatic deaths, and also among premature neonates (categories 9 and 11). Intrapartum hypoxia was more common than malformation as a cause of death in males; the female preponderance among malformed infants was due in part to an excess of females with neural tube defects. The majority of perinatal deaths from malformation occurred in neonates, but $11 \%$ of antepartum deaths had lethal malformations.

Most of the Rhesus deaths were in the neonatal period, and the antepartum deaths occurred despite intra-uterine transfusion in severely affected infants. Intrapartum hypoxia was the most common cause of intrapartum death but was also responsible for $15 \%$ of neonatal deaths. Intracranial traumatic lesions accounted for only $4 \%$ of neonatal deaths. Necropsy findings associated particularly with prematurity (categories 9, 11, and 12) caused one-third of early neonatal deaths, while a further one-quarter of neonates were malformed. Intraventricular haemor- 


\begin{tabular}{|c|c|c|c|c|c|c|c|c|c|c|c|c|c|c|c|}
\hline \multirow{2}{*}{\multicolumn{2}{|c|}{$\begin{array}{l}\text { Primary Necropsy } \\
\text { Finding }\end{array}$}} & \multicolumn{3}{|c|}{ Antepartum } & \multicolumn{3}{|c|}{ Intrapartum } & \multicolumn{3}{|c|}{ Neonatal } & \multicolumn{5}{|c|}{ All Perinatal Deaths } \\
\hline & & $M$ & $F$ & Total & $M$ & $F$ & Total & $M$ & $F$ & Total & $M$ & $F$ & Total & $\%$ & $\begin{array}{l}\text { Sex } \\
\text { Ratio }\end{array}$ \\
\hline 1 & Malformation & 8 & 13 & 21 & 19 & 33 & 52 & 52 & 48 & 100 & 79 & 94 & 173 & $23 \cdot 8$ & 0.84 \\
\hline 2 & Isoimmunization & 5 & 4 & 9 & 0 & 0 & 0 & 9 & 6 & 15 & 14 & 10 & 24 & $3 \cdot 3$ & 1.40 \\
\hline \multirow[t]{2}{*}{3} & $\begin{array}{l}\text { Antepartum death, } \\
\text { no major lesion }\end{array}$ & & & & & & & & & & & & & & \\
\hline & & 10 & 11 & 21 & 0 & $\mathbf{0}$ & 0 & 0 & 0 & 0 & 10 & 11 & 21 & $2 \cdot 9$ & 0.91 \\
\hline $\begin{array}{l}4 \\
5\end{array}$ & Intrapartum hypoxia & $\begin{array}{r}73 \\
0\end{array}$ & 60 & 133 & 0 & 0 & 0 & 0 & 0 & 0 & 73 & 60 & 133 & $18 \cdot 3$ & $1 \cdot 22$ \\
\hline \multirow{2}{*}{6} & & 0 & 0 & 0 & 57 & 40 & 97 & 36 & 19 & 55 & 93 & 59 & 152 & 20.9 & $1 \cdot 58$ \\
\hline & with cerebral trauma & 0 & 1 & 1 & 8 & 2 & 10 & 8 & 3 & 11 & 16 & 6 & 22 & $3 \cdot 0$ & 2.67 \\
\hline 7 & Cerebral birth trauma & $\mathbf{0}$ & 0 & 0 & 0 & 0 & 0 & 5 & 2 & 7 & 5 & 2 & 7 & $1 \cdot 0$ & $2 \cdot 50$ \\
\hline 8 & Pneumonia & 0 & 0 & 0 & $\mathbf{0}$ & 0 & $\mathbf{0}$ & 21 & 15 & 36 & 21 & 15 & 36 & $5 \cdot 0$ & $1 \cdot 40$ \\
\hline 9 & Hyaline membranes & 0 & 0 & 0 & 0 & 0 & $\mathbf{0}$ & 27 & 18 & 45 & 27 & 18 & 45 & $6 \cdot 2$ & $1 \cdot 50$ \\
\hline \multirow{2}{*}{10} & Pulmonary & & & & & & & & & & & & & & \\
\hline & haemorrhage & 0 & 0 & 0 & 0 & 0 & 0 & 3 & 6 & 9 & 3 & 6 & 9 & $1 \cdot 2$ & 0.50 \\
\hline 11 & haemorrhage & 0 & 0 & 0 & 0 & 0 & 0 & 46 & 31 & 77 & 46 & 31 & 77 & 10.6 & $1 \cdot 48$ \\
\hline 12 & $\begin{array}{l}\text { Neonatal death, } \\
\text { no major lesion }\end{array}$ & 0 & 0 & 0 & 0 & 0 & 0 & 2 & 2 & 4 & 2 & 7 & $A$ & 0.6 & 190 \\
\hline \multirow[t]{2}{*}{13} & Extrapulmonary & & 0 & 0 & 0 & 0 & 0 & 2 & 2 & & 2 & 2 & 4 & 0.0 & 1.00 \\
\hline & infection & 0 & 0 & 0 & 1 & 0 & 1 & 5 & 3 & 8 & 6 & 3 & 9 & $2 \cdot 4$ & $2 \cdot 00$ \\
\hline \multirow[t]{2}{*}{15} & Miscellaneous & 0 & 0 & 0 & 1 & 0 & 1 & 8 & 5 & 13 & 9 & 5 & 14 & 1.9 & $1 \cdot 80$ \\
\hline & Total & 96 & 89 & 185 & 86 & 75 & 161 & 222 & 158 & 380 & 404 & 322 & 721 & 100 & $1 \cdot 25$ \\
\hline
\end{tabular}

Table I Primary necropsy findings in 726 perinatal deaths, by sex and stage of death in relation to labour

rhage was found in $20 \%$ of neonates and in $11 \%$ of all perinatal deaths.

Eight infants died of extrapulmonary infections. There were two cases of toxoplasmosis and two of Escherichia coli septicaemia. Streptococci were isolated from one case of meningitis, but the causative organism was not isolated in the two other (treated) cases. There was one case of herpes hepatitis.

Miscellaneous conditions (category 15) were found in 14 infants; these were:
7 cases-aspiration of gastric contents, no other cause found

2 cases-meconium peritonitis, cause not established

3 cases-pneumothorax; one case had bilateral haemothoraces

1 case - ruptured liver with haemoperitoneum

1 case - sudden unexplained death (cot death).

The distribution of these primary necropsy categories in the 1958 survey and the present survey are

\begin{tabular}{|c|c|c|c|c|c|c|c|c|c|c|c|c|}
\hline \multirow{3}{*}{$\begin{array}{l}\text { Primary } \\
\text { Necropsy } \\
\text { Category }\end{array}$} & \multicolumn{6}{|c|}{ Percent of Deaths } & \multicolumn{6}{|c|}{ Per 1000 births } \\
\hline & \multicolumn{2}{|c|}{ Stillbirths } & \multicolumn{2}{|c|}{$\begin{array}{l}\text { Neonatal } \\
\text { Deaths }\end{array}$} & \multicolumn{2}{|c|}{$\begin{array}{l}\text { Perinatal } \\
\text { Deaths }\end{array}$} & \multicolumn{2}{|c|}{ Stillbirths } & \multicolumn{2}{|c|}{$\begin{array}{l}\text { Neonatal } \\
\text { Deaths (per } \\
1000 \text { liveborn) }\end{array}$} & \multicolumn{2}{|c|}{$\begin{array}{l}\text { Perinatal } \\
\text { Deaths }\end{array}$} \\
\hline & 1958 & Present & 1958 & Present & 1958 & Present & 1958 & Present & 1958 & Present & 1958 & Present \\
\hline 1 & $17 \cdot 5$ & $21 \cdot 1$ & $21 \cdot 6$ & $26 \cdot 3$ & $19 \cdot 0$ & $23 \cdot 8$ & $3 \cdot 5$ & $2 \cdot 5$ & $2 \cdot 4$ & $2 \cdot 5$ & $5 \cdot 8$ & 5.0 \\
\hline 2 & 4.4 & $2 \cdot 6$ & $4 \cdot 2$ & 3.9 & $4 \cdot 3$ & $3 \cdot 3$ & 0.9 & $0 \cdot 3$ & $0 \cdot 5$ & 0.4 & $1 \cdot 3$ & $0 \cdot 7$ \\
\hline 3 & $17 \cdot 0$ & $6 \cdot 1$ & - & - & $10 \cdot 9$ & 2.9 & 3.4 & 0.7 & - & - & $3 \cdot 4$ & 0.6 \\
\hline 4 & $17 \cdot 4$ & $38 \cdot 6$ & - & - & $11 \cdot 2$ & $18 \cdot 4$ & $3 \cdot 4$ & $4 \cdot 5$ & - & - & $3 \cdot 4$ & $3 \cdot 8$ \\
\hline 5 & $30 \cdot 8$ & $27 \cdot 8$ & 8.7 & $14 \cdot 5$ & 22.9 & $20 \cdot 9$ & $6 \cdot 1$ & 3.7 & 1.0 & 1.4 & $7 \cdot 1$ & 4.4 \\
\hline 6 & 7.8 & $3 \cdot 2$ & $5 \cdot 3$ & 2.9 & 6.9 & 3.0 & 1.5 & 0.4 & 0.6 & 0.3 & $2 \cdot 1$ & 0.6 \\
\hline 7 & 1.7 & - & $5 \cdot 6$ & $1 \cdot 8$ & $3 \cdot 1$ & 1.0 & 0.3 & - & 0.6 & 0.2 & $1 \cdot 0$ & 0.2 \\
\hline 8 & - & - & $13 \cdot 3$ & $9 \cdot 5$ & $4 \cdot 8$ & $5 \cdot 0$ & - & - & 1.5 & 0.9 & 1.5 & 1.0 \\
\hline 9 & - & - & $15 \cdot 0$ & $11 \cdot 8$ & $5 \cdot 3$ & $6 \cdot 2$ & - & - & 1.7 & $1 \cdot 1$ & 1.6 & $1 \cdot 3$ \\
\hline 10 & - & - & 5.9 & $2 \cdot 4$ & $2 \cdot 1$ & $1 \cdot 2$ & - & - & 0.7 & 0.2 & 0.6 & 0.3 \\
\hline 11 & - & - & 6.4 & $20 \cdot 2$ & $2 \cdot 3$ & $10 \cdot 6$ & - & - & 0.7 & 1.9 & 0.7 & $2 \cdot 2$ \\
\hline 12 & - & - & $8 \cdot 7$ & $1 \cdot 1$ & $3 \cdot 1$ & 0.6 & - & - & 1.0 & $0 \cdot 1$ & 1.0 & $0 \cdot 1$ \\
\hline 13 & - & 0.3 & 1.0 & $2 \cdot 1$ & 0.4 & $1 \cdot 2$ & - & $<0.1$ & $0 \cdot 1$ & 0.2 & $0 \cdot 1$ & 0.5 \\
\hline 14 & $2 \cdot 8$ & 0.0 & - & - & $1 \cdot 8$ & 0.0 & 0.6 & 0.0 & - & - & 0.6 & 0.0 \\
\hline 15 & 0.6 & $0 \cdot 3$ & $1 \cdot 6$ & $3 \cdot 4$ & 0.9 & $1 \cdot 9$ & $0 \cdot 1$ & $<0 \cdot 1$ & $0 \cdot 2$ & 0.3 & $0 \cdot 3$ & 0.4 \\
\hline Total & $100 \cdot 0$ & $100 \cdot 0$ & $97 \cdot 3^{1}$ & $100 \cdot 0$ & $99 \cdot 0^{1}$ & $100 \cdot 0$ & $19 \cdot 8$ & $12 \cdot 1$ & $11 \cdot 0$ & $9 \cdot 5$ & $30 \cdot 5$ & $21 \cdot 1$ \\
\hline
\end{tabular}

Table II Distribution of primary necropsy categories among stillbirths, early neonatal deaths, and all perinatal deaths, and per 1000 births: Comparison of 1958 and present survey

${ }^{1}$ The remainder were not necropsied. 
compared in table II. This shows that malformation is now proportionately more common among perinatal deaths than previously, but that the actual number of infants born with lethal malformations is slightly less than was the case in 1958 (5.0 and 5.8 per 1000 births respectively). The contribution of lethal neural tube malformations was 3.3 per 1000 in 1958 , and 2.0 per 1000 in the present survey.

There has been a great reduction in intra-uterine deaths from Rhesus disease, and the overall death rate per 1000 births has been halved.

Antepartum deaths (categories 3 and 4) constituted $21-22 \%$ of perinatal deaths in both surveys but fell from 6.8 to 4.4 per 1000 births. Similar figures apply to intrapartum hypoxic deaths (category 5). The greatest reduction since 1958 has occurred among traumatic deaths (categories 6 and 7), which accounted for 10.0 and $4.0 \%$ of perinatal deaths respectively, with a corresponding fall in incidence per 1000 births.

Within the perinatal death group, pneumonia (category 8 ) has declined from 1.5 to 1.0 deaths per 1000 births. In contrast, there would appear to have been a great increase in extrapulmonary infection among perinatal deaths and a fivefold increase in such perinatal infections per 1000 births.

While the frequency of hyaline membrane disease has declined among perinatal deaths, there appears to have been a threefold increase in lethal intraventricular haemorrhage per 1000 liveborn infants and a fivefold increase in its contribution to perinatal death.

This is further analysed in table III, which compares some groups of necropsy categories by gestational age ('premature' and 'mature' groups). The reduction in perinatal mortality has occurred mainly in the 'mature' group, which previously constituted

\begin{tabular}{|c|c|c|c|c|c|c|}
\hline \multirow[t]{3}{*}{ Necropsy Category } & \multicolumn{6}{|c|}{ Gestational Age } \\
\hline & \multicolumn{2}{|c|}{ 28-35 weeks } & \multicolumn{2}{|c|}{$36-42$ weeks } & \multicolumn{2}{|l|}{ Total } \\
\hline & 1958 & Present & 1958 & Present & 1958 & Present \\
\hline Malformation (1) & $2 \cdot 3$ & 1.7 & 3.5 & $3 \cdot 3$ & 5.8 & 5.0 \\
\hline $\begin{array}{l}\text { Antepartum death } \\
(3+4)\end{array}$ & $2 \cdot 7$ & $2 \cdot 0$ & $4 \cdot 1$ & $2 \cdot 4$ & $6 \cdot 8$ & $4 \cdot 4$ \\
\hline $\begin{array}{l}\text { Intrapartum } \\
\text { hypoxia and/or } \\
\text { trauma }(5,6,7)\end{array}$ & $2 \cdot 5$ & $2 \cdot 6$ & $7 \cdot 7$ & $2 \cdot 6$ & $10 \cdot 2$ & $5 \cdot 2$ \\
\hline $\begin{array}{l}\text { Hyaline membrane } \\
\text { disease (9) }\end{array}$ & $1 \cdot 3$ & 0.9 & $0 \cdot 3$ & $0 \cdot 4$ & $1 \cdot 6$ & $1 \cdot 3$ \\
\hline $\begin{array}{l}\text { Intraventricular } \\
\text { haemorrhage (11) }\end{array}$ & 0.7 & 1.8 & $<0 \cdot 1$ & $0 \cdot 4$ & $0 \cdot 7$ & $2 \cdot 2$ \\
\hline $\begin{array}{l}\text { Others }(2,8,10 \\
12-15)\end{array}$ & $3 \cdot 2$ & $2 \cdot 1$ & 4.9 & 0.9 & $8 \cdot 1$ & $3 \cdot 0$ \\
\hline All deaths & $12 \cdot 7$ & $11 \cdot 1$ & 20.5 & $10 \cdot 0$ & $33 \cdot 2$ & $21 \cdot 1$ \\
\hline
\end{tabular}

Table III Distribution per 1000 births of certain primary necropsy categories by gestational age two-thir ds of perinatal deaths. Antepartum and intrapartum hypoxia now results in a much smaller proportion of perinatal deaths in mature infants than in 1958 , but there has also been a general reduction in the miscellaneous categories. Among premature infants, there has been a reduction in antepartum stillbirths, hyaline membrane disease, and miscellaneous categories, while the frequency of intraventricular haemorrhage has almost trebled.

\section{Body weight}

Seventy per cent of perinatal deaths weighed less than $2500 \mathrm{~g}$, the body weight corresponding with 36 weeks' gestation. The primary necropsy findings in these infants were as for low gestational age, while infants weighing more than $2500 \mathrm{~g}$ died of categories $6,7,10$, and 15 . Thirty-six per cent of intrapartum and neonatal deaths were small for dates, that is, more than one standard deviation below the mean weight for gestational age as confidently given by the mother, and using the data from Butler and Alberman (1969). Small-for-dates infants were found in most of the necropsy categories, but particularly in 1, 8 , and 9. Most of the small-for-dates infants were born before 36 weeks' gestation, and $43 \%$ of infants born at 32-35 weeks were small for dates.

\section{Length of survival}

Half of the early neonatal deaths occurred within the first 24 hours; there was then a progressive decrease until the seventh day, when there was a peak caused by the deaths of some infants with multiple and cardiovascular malformations, and with infections. All of the necropsy categories show the greatest death rate in the first 24 hours apart from intraventricular haemorrhage, which had a maximal frequency at 1 to 3 days.

\section{Multiple pregnancies}

There were 67 infants $(9 \%)$ who were the products of multiple pregnancies. There were 60 twins from 43 pregnancies, five triplets from five pregnancies, and two quadruplets from one pregnancy. There was one pair of conjoined thoracopagus twins. In 18 twin pregnancies both twins died, but in 25 cases only one twin died; in 19 cases, this was the second twin. Hypoxia, hyaline membrane disease, and intraventricular haemorrhage accounted for most of the deaths; malformation was less frequent in twins than in singletons, but it was found in three of the five triplets. One of the quadruplets died of hyaline membrane disease and the other of hypoxia. In 1958, $9 \%$ of perinatal deaths were in multiple pregnancies, amounting to three perinatal deaths per 1000 births. The present frequency is two perinatal deaths per 1000 births. 


\section{LETHAL MALFORMATIONS}

These were found in almost one-quarter of perinatal deaths and are analysed in table IV by stage of death and by organ system involved. More than half of the infants had malformations affecting more than one organ system in such a way that no one malformation could be held to have resulted in the secondary appearance of the other malformations. In several cases there were lethal and complex malformations affecting up to seven organ systems per infant.

The single malformations are listed by organ systems in table V. All the single malformations of the central nervous system were variants of major neural tube defects, that is, anencephalus, myelomeningocoele or hydrocephalus. Among genito-urinary malformations, bilateral renal agenesis and bilateral cystic renal dysplasia were the common findings.

\begin{tabular}{lllll}
\hline Organ System & \multicolumn{4}{l}{ Stage of Death } \\
\cline { 2 - 5 } & Antepartum & Intrapartum & Neonatal & Total \\
\hline Multiple & 14 & 29 & 46 & 89 \\
Central nervous & 3 & 15 & 11 & 29 \\
Cardiovascular & 1 & 0 & 12 & 13 \\
Genitourinary & 1 & 0 & 15 & 16 \\
Gastrointestinal & 2 & 1 & 1 & 4 \\
Other & 0 & 7 & 15 & 22 \\
Total & 21 & 52 & 100 & 173 \\
\hline
\end{tabular}

Table IV Malformations: organ systems by stage of death

\begin{tabular}{|c|c|c|}
\hline $\begin{array}{l}\text { Central nervous system: } \\
\text { Hydrocephalus with }\end{array}$ & 29 & Diaphragmatic hernia: \\
\hline myelomeningocoele & 10 & Pulmonary hypoplasia: \\
\hline Anencephalus & 9 & Adenomatoid cystic \\
\hline Craniorachischisis & 4 & lung: \\
\hline Occipital & & \\
\hline $\begin{array}{c}\text { encephalocoele } \\
\text { Hydrocephalus only }\end{array}$ & $\begin{array}{l}4 \\
2\end{array}$ & $\begin{array}{l}\text { Miscellaneous malforma- } \\
\text { tions: }\end{array}$ \\
\hline Genito-urinary system: & 16 & $\begin{array}{l}\text { Idiopathic hydrops } \\
\text { Osteogenesis }\end{array}$ \\
\hline Cystic dysplasia & 6 & imperfecta \\
\hline Bilateral agenesis & 4 & Intra-uterine \\
\hline Unilateral agenesis & 2 & amputation \\
\hline Others & 4 & $\begin{array}{l}\text { Cystic fibrosis } \\
\text { (meconium ileus) }\end{array}$ \\
\hline Cardiovascular system: & 13 & $\begin{array}{l}\text { Thanatophoric } \\
\text { dwarfism }\end{array}$ \\
\hline $\begin{array}{l}\text { Complex malformations } \\
\text { Left heart hypoplasia }\end{array}$ & $\begin{array}{l}6 \\
5\end{array}$ & Others \\
\hline $\begin{array}{l}\text { Transposition } \\
\text { VSD }\end{array}$ & 1 & $\begin{array}{l}\text { Total single malforma- } \\
\text { tions: }\end{array}$ \\
\hline Gastrointestinal system: & 4 & \\
\hline $\begin{array}{l}\text { Tracheo-oesophageal } \\
\text { fistula }\end{array}$ & 3 & \\
\hline Multiple small gut & & \\
\hline atresia & 1 & \\
\hline
\end{tabular}

Table V Single malformations by organ system
Very severe anatomical abnormalities characterized the congenital heart defects seen among perinatal deaths. Left heart hypoplasia was the most common single cardiac malformation; various combinations of mitral atresia, aortic atresia, small left ventricular cavity, and preductal aortic arch anomalies were found in this condition, which was often accompanied by subendocardial fibro-elastosis.

In 89 infants, malformations affected more than one organ system. Central nervous, genito-urinary, and cardiovascular malformations were the most common; on average, there were three major malformations per infant.

Table VI compares the malformed infants found in 1958 and in the present survey. Cardiovascular, genito-urinary, and alimentary malformations were seen more frequently in the present survey, but the overall reduction in deaths from malformation per 1000 births as compared with 1958 was largely accounted for by a halving of the incidence of anencephaly.

\begin{tabular}{|c|c|c|c|c|c|}
\hline \multicolumn{2}{|c|}{ Organ System } & \multicolumn{2}{|c|}{$\begin{array}{l}\% \text { Deaths from } \\
\text { Malformation }\end{array}$} & \multicolumn{2}{|c|}{ Per 1000 Births } \\
\hline & & 1958 & Present & 1958 & Present \\
\hline \multirow{4}{*}{$\begin{array}{l}\text { Central } \\
\text { nervous }\end{array}$} & Anencephalus & 39 & 24 & $2 \cdot 3$ & $1 \cdot 2$ \\
\hline & $\begin{array}{l}\text { Myelomeningocoele } \\
\text { with hydrocephalus }\end{array}$ & 13 & 9 & 0.8 & 0.5 \\
\hline & Hydrocephalus only & 5 & 5 & $0 \cdot 3$ & $0 \cdot 3$ \\
\hline & Other & 9 & 12 & $0 \cdot 5$ & 0.6 \\
\hline
\end{tabular}

All central nervous system

$\begin{array}{llll}66 & 50 & 3 \cdot 9 & 2 \cdot 5\end{array}$

Alimentary Oesophageal atresia
Other $\begin{array}{rrrr}5 & 7 & 0.3 & 0 \cdot 3 \\ 11 & 20 & 0.6 & 1 \cdot 0\end{array}$

\begin{tabular}{rrrr}
5 & 7 & 0.3 & 0.3 \\
11 & 20 & 0.6 & 1.0 \\
16 & 27 & 0.9 & $1 \cdot 3$ \\
& & & \\
8 & 11 & 0.5 & 0.5 \\
24 & 43 & $1 \cdot 4$ & $2 \cdot 1$ \\
21 & 19 & $1 \cdot 3$ & $1 \cdot 0$ \\
20 & 37 & 1.2 & 1.8 \\
20 & 28 & $1 \cdot 2$ & $1 \cdot 4$ \\
100 & 100 & $5 \cdot 8$ & 5.0 \\
\hline
\end{tabular}

All alimentary system

Diaphragmatic hernia

Genitourinary system

Skeletal

Cardiovascular

Other

Total lethally malformed infants

Table VI Lethal malformations by organ system: Comparison of 1958 and present survey

(Malformation categories not mutually exclusive)

CHROMOSOME ANALYSIS

Chromosome results were obtained from 500 of the 726 infants. The 28 abnormal results $(5.6 \%)$ are listed in table VII. Thirteen per cent of lethally malformed infants were chromosomally abnormal, and many of these had multisystem malformations that did not include the common neural tube anomalies, anencephalus, myelomeningocoele, and hydrocephalus. Although few results were obtained from macerated 


\begin{tabular}{|c|c|c|}
\hline $\begin{array}{l}\text { 46, XY, normal male } \\
47, \mathrm{XY},+\mathrm{D} \text { (Patau's } \\
\text { syndrome) } \\
47, \mathrm{XY},+\mathrm{E} \text { (Edwards' } \\
\text { syndrome) } \\
47, \mathrm{XXY} \quad \begin{array}{c}\text { (Klinefelter's } \\
\text { syndrome) }\end{array} \\
46, \mathrm{XYXX} 47, \mathrm{XXY} \\
45, \mathrm{XY}, \\
-\mathrm{D},-\mathrm{G},+\mathrm{t}(\mathrm{DqGG}) \\
69, \mathrm{XXY} \text { (triploidy) }\end{array}$ & $\begin{array}{l}2 \\
1\end{array}$ & $\begin{array}{l}\text { 46, XX, normal female } \\
47, X X,+D \\
47, X X,+E \\
47, X X,+G \text { (Down's } \\
\text { syndrome) } \\
\text { 47, XX, +t(GqGq) } \\
\text { 45, XX, - D, - D, +t(DqDq) } \\
\text { 46, XX, - D, +t(DqGq) } \\
\text { 46, XX, t(12q17q) } \\
\text { 46, XX, - G, +t(16p21p) } \\
\text { 46, XX, Gp- } \\
\text { 46, XX, Dp - } \\
\text { 45, X } \\
\text { (Turner's syndrome) }\end{array}$ \\
\hline
\end{tabular}

Table VII The chromosome results

stillbirths, $9 \%$ of these were chromosomally abnormal.

OTHER GENETIC DISEASES

The following were recognized among the 726 infants:

Autosomal recessive:

Ellis-van Creveld type of dwarfism 2 cases

Cystic fibrosis of pancreas (meconium ileus)

Juvenile familial cystic renal disease 1 case

Citrullinaemia

1 case

Sex-linked:

Sex-linked hydrocephalus 1 case

Sporadic:

Osteogenesis imperfecta gravis 2 cases

Thanatophoric dwarfism 1 case

\section{Discussion}

The perinatal necropsy has both retrospective and prospective implications. Its first function is to find the lesions which have caused death, and to relate these to the clinical history. Secondly, factors may be found that identify the mother as being at risk for obstetric complications in future pregnancies. The perinatal necropsy may also be the means by which new agents are identified. In addition, the accurate delineation of malformations mayallow the diagnosis of heritable defects and syndromes in families who could not otherwise be given adequate genetic counselling. In some cases, the necropsy findings may indicate that antenatal diagnosis should be offered in any subsequent pregnancies. Finally, the perinatal necropsy allows the collection of statistical data that cannot be compiled reliably from death certificates alone.

In comparing the results of the 1958 survey and the present work the main differences are:

1 There has been a reduction in the proportion of perinatal deaths that were stillborn, intrapartum deaths showing the greatest decline. This is probably explained both by improved antenatal care of women at risk and by intrapartum monitoring of the foetus.

2 Among necropsy categories, the largest changes are seen among traumatic deliveries, intraventricular haemorrhage, and extrapulmonary infection. The reasons for the decline in traumatic deaths are as discussed above, and, since such deaths were most common among mature infants, there has been a consequent reduction in mature infants dying in the perinatal period. Among premature neonates dying in the perinatal period, there has been an absolute increase in intraventricular haemorrhage from 0.7 to $2 \cdot 2$ per 1000 births. There are several possible explanations for this increase; there has been a corresponding decrease in hyaline membrane disease among premature neonatal deaths, suggesting that intraventricular haemorrhage (which causes death later than hyaline membrane disease) supervenes in these premature infants who now receive resuscitation and intensive care. By the same reasoning, it is possible that some of these infants would previously have died from intrapartum hypoxia and/or trauma; however, reference to table III shows no reduction in premature hypoxic deaths per 1000 births. Nor is there a significant increase in the incidence of prematurity, since $6.7 \%$ of all births in 1958 had a body weight of less than $2.5 \mathrm{~kg}$ compared with $7.2 \%$ in 1972 (Department of Health and Social Security, 1973). Finally, intraventricular haemorrhage is now diagnosed frequently in life and recognized at necropsy.

The increase in extrapulmonary infection from $0 \cdot 1$ to 0.5 perinatal deaths per 1000 births is probably explicable in terms of increasing recognition and diagnosis during life and at necropsy, rather than as an absolute increase in incidence.

3 In 1958 lethal malformations were found in $19 \%$ of infants dying in the perinatal period. In the present survey the proportion was $24 \%$. In 1958 there were 5.8 lethally malformed infants per 1000 births, while the present figure was 5.0 per 1000 . Claireaux (1973) reported that $20 \%$ of infants dying in the British Births Survey, 1970, were lethally malformed, and that these represented 5 per 1000 births. Table VI shows that in 1958 there were 2.3 anencephalics and 3.4 lethal tube defects per 1000 births in England, Scotland, and Wales. In London and south-east England, the frequencies were 1.8 and 3.3 respectively. In the present survey, anencephaly and lethal neural tube defects were found in 1.2 and 2.0 per 1000 births. In 1971, there were 1.4 anencephalics and 3.9 neural tube defects (lethal and otherwise) per 1000 births in England and Wales (Department of Health and Social Security, 1973). Thus, the overall reduction 
in malformation as a cause of perinatal death is largely accounted for by a decreased incidence of anencephalus. The antenatal diagnosis of neural tube defects will lead to a further reduction in their contribution to perinatal death, but there is no immediate prospect of antenatal diagnosis of malformations in other organ systems.

The incidence of chromosome abnormalities in this survey $(5.6 \%)$ is ten times that found in unselected newborn infants (Sergovich et al, 1969; Court Brown and Smith, 1969; Hamerton et al, 1972). Indeed, it appears that chromosome abnormality is now more important numerically than Rhesus disease among perinatal deaths. The majority of chromosomally abnormal infants were not identified as such at birth. The results of this survey suggest that chromosome analyses should ideally be undertaken in all perinatal deaths, and certainly in all antepartum stillbirths and infants with multisystem malformations excluding anencephalus, myelomeningocoele, and hydrocephalus.

In this survey, three groups of families were ascertained to whom antenatal diagnosis could be offered in any subsequent pregnancy. Of the karyotyped infants $5.6 \%$ were chromosomally abnormal; a further 38 of the 706 families $(5.4 \%)$ had had infants with neural tube defects; there was one family with a sex-linked inherited disease. Thus, roughly $10 \%$ of these families could be offered help as a result of the findings at perinatal necropsy. The next few years will probably see a further reduction in perinatal deaths among premature infants, leaving a residue with a proportionately larger content of malformation and genetic disease. The ascertainment and counselling of families with genetic disorders will continue to be an important function of the perinatal necropsy.

This work was carried out with the aid of grants from the Medical Research Council and the Research Fund of the University of London. I am grateful to Professor P. E. Polani for guidance and discussion of this work. Many pathologists, obstetricians, and paediatricians supported the work by their co-operation and interest.

\section{References}

Butler, N. R. and Bonham, D. G. (1963). Perinatal Mortality: The First Report of the 1958 British Perinatal Survey. Livingstone, Edinburgh.

Butler, N. R. and Alberman, E. D. (1969). Perinatal Problems: The Second Report of the 1958 British Perinatal Mortality Survey. Livingstone, Edinburgh.

Claireaux, A. E. (1973). Fetal abnormalities as cause of perinatal death. Proc. roy. Soc. Med., 66, 1119-1120.

Court Brown, W. M. and Smith, P. G. (1969). Human population cytogenetics. Brit. med. Bull., 25, 74-80.

Department of Health and Social Security (1973). On the State of the Public Health, 1972. HMSO, London.

Fairweather, D. V. I., Russell, J. K., Anderson, G. S., Bird, T., Millar, D. G., and Pearcy, P. A. M. (1966). $\infty$ Perinatal mortality in Newcastle-upon-Tyne 1960-62. Lancet, 1, 140-142.

Fedrick, J. and Butler, N. R. (1970a). Certain causes of $\stackrel{+}{N}$ neonatal death. I. Hyaline membranes. Biol. Neonat. (Basel), 15, 229-255.

Fedrick, J. and Butler, N. R. (1970b). Certain causes of $\vec{c}$ neonatal death. II. Intraventricular haemorrhage. Biol. Neonat. (Basel), 15, 257-290.

Fedrick, J. and Butler, N. R. (1971a). Certain causes of neonatal death. III. Pulmonary infection (a) clinical factors. Biol. Neonat. (Basel), 17, 458-471.

Fedrick, J. and Butler, N. R. (1971b). Certain causes of neonatal death. III. Pulmonary infection (b) pregnancy and delivery. Biol. Neonat. (Basel), 18, 45-57.

Fedrick, J. and Butler, N. R. (1971c). Certain causes of neonatal death. IV. Massive pulmonary haemorrhage. Biol. Neonat. (Basel), 18, 243-262.

Gluck, L., Kulovich, M. V., Borer, R. C., Jr., Brenner, P. H., @ Anderson, G. G., and Spellacy, W. N. (1971). Diagnosis of the respiratory distress syndrome by amniocentesis. Amer. J. Obstet. Gynec., 109, 440-445.

Gruenwald, P. and Minh, H. N. (1960). Evaluation of body and organ weights in perinatal pathology. I. Normal standards derived from autopsies. Amer.J. clin. Path., 34, 247-253.

Hamerton, J. L., Ray, M., Abbott, J., Williamson C., and Ducasse, G. C. (1972). Chromosome studies in a neonatal population. C.M.A.J., 106, 776-779.

Langley, F. A. (1971). The perinatal postmortem examination. J. clin. Path., 24, 159-169.

Liggins, G. C., and Howie, R. N. (1972). A controlled trial of antepartum glucocorticoid treatment for prevention of the respiratory distress syndrome in premature infants. Pediatrics, 50, 515-525.

Machin, G. A. (1974). Chromosome abnormality and perinatal death. Lancet, 1, 549-551.

Sergovich, F., Valentine, G. H., Chen, A. T. L., Kinch, R. A. H., and Smout, M. S. (1969). Chromosome aberrations in 2159 consecutive newborn babies. New. Engl. $J$. Med., 280, 851-855. 